\title{
Quantification of allele-specific G-protein $\beta 3$ subunit mRNA transcripts in different human cells and tissues by Pyrosequencing
}

\author{
Aijun Sun ${ }^{1}$, Junbo Ge ${ }^{1}$, Winfried Siffert ${ }^{2}$ and Ulrich H Frey ${ }^{\star 2}$ \\ ${ }^{1}$ Institute of Cardiovascular Disease, Zhongshan Hospital, Fudan University, P.R. China; ${ }^{2}$ Institute of Pharmacology, \\ Medical Faculty, University of Essen, Germany
}

The G-protein 825T allele is associated with altered drug responses while the underlying mechanism is not fully understood. Differential expression of transcripts from the $C$ and $T$ alleles could contribute to this process. The C825T polymorphism located in exon 10 is in close linkage disequilibrium with the $A(-350) G$ promoter single nucleotide polymorphism (SNP) and the C1429T SNP and could therefore serve as a marker for allele-specific expression resulting from the promoter SNP. However, alternative splicing of exon 10 in $825 \mathrm{~T}$ allele carriers may result in under-represented mRNA transcripts. We, therefore, established a novel method based on the Pyrosequencing technology to quantify allele-specific transcript expression and quantified the allelic variance of the C1429T polymorphism located in the $3^{\prime}$-untranslated region of GNB3. Validation of the method was performed using linear regression analysis of measured versus expected ratios of DNA mixed at different known concentrations as well as determining allelespecific mRNA expression of the partially imprinted IGF-2 gene. We genotyped the C1429T polymorphism of 83 samples derived from six different human tissues and cell lines and quantified mRNA transcripts from different alleles using heterozygous samples. No significantly different transcript amounts from the two alleles were found. There were also no significantly different transcript amounts associated with different $G(-350)$ A genotypes $(P>0.05)$. As a result, we could show that Pyrosequencing provides a sensitive tool to quantify allele-specific transcript expression. Our data do not support the hypothesis that differential G-protein activity associated with the C825T SNP results from different transcript amounts associated with specific GNB3 genotypes.

European Journal of Human Genetics (2005) 13, 361-369. doi:10.1038/sj.ejhg.5201334

Published online 10 November 2004

Keywords: G-protein; genetic polymorphism; allele quantification; Pyrosequencing; imprinting

\section{Introduction}

The G-protein 825T allele serves as a pharmacogenetic marker to predict responses to different drugs, for example, diuretics, ${ }^{1}$ antidepressants, ${ }^{2}$ sildenafil,${ }^{3}$ clonidine, ${ }^{4}$ and sibutramine, ${ }^{5}$ to name but a few. Furthermore, the $825 \mathrm{~T}$

${ }^{*}$ Correspondence: $\operatorname{Dr} U$ Frey, Institute of Pharmacology, University Hospital, Hufelandstrasse 55, D-45122 Essen, Germany. Tel: +49201 723 3459; Fax: + 49201723 5968; E-mail: ulrich.frey@uni-essen.de Received 13 July 2004; revised 27 September 2004; accepted 6 October 2004 allele is associated with enhanced signal transduction in human cells and tissues such as B lymphoblasts, ${ }^{6}$ neutrophils, $^{7}$ T lymphocytes, ${ }^{8}$ and fat cells. ${ }^{9}$ However, the biochemical and molecular mechanisms underlying these associations were not yet fully understood.

The 825T allele is located in exon 10 of GNB3 and nucleotide substitutions located in intron 9 of GNB3 are potentially associated with alternative splicing of exons 9 and 10 , or both, which results in the generation of short splice variants termed G $\beta 3$-s or G $\beta 3$-s2. ${ }^{6,10}$ Carriers of the 
825T allele express the wild-type variant and G $\beta 3$-s and/or G $\beta 3$-s 2 while carriers of the CC genotype predominantly express wild-type $\mathrm{G} \beta 3$. Most studies suggest that $\mathrm{G} \beta 3$ splice variants overexpressed in vitro can interact with $\mathrm{G} \gamma$ subunits and activate intracellular effector pathways more efficiently than wild-type G $\beta 3 .^{7,11}$ The $825 \mathrm{~T}$ allele was once considered as 'loss of structure, gain of function' variant, while some experiments showed controversial results. ${ }^{12}$ However, so far the G $\beta 3$ splice variants were detected in different cells mainly by means of RT-PCR, while more direct evidence for the actual expression of $\mathrm{G} \beta 3$-s and G $\beta 3$ s2 protein is lacking.

Using Western blot analysis, Ryden et $a l^{9}$ reported that the amount of wild-type $\mathrm{G} \beta 3$ protein is lowest in fat cells from individuals with the TT genotype and highest from CC genotype, TC genotype displaying intermediate levels. Nevertheless in this latter study, signal transduction was strongest in cells from individuals with TT genotype despite reduced expression of wild-type G $\beta 3$ and no evidence for expression of $\mathrm{G} \beta 3$ s on the protein level.

In previous studies, we have defined the major haplotypes of GNB3. A 'GNB3 C-haplotype' consists of the 825Callele, the $1429 \mathrm{C}$-allele, and the $(-350 \mathrm{G})$ allele, and a 'GNB3 T-haplotype' consists of the 825T-allele, the 1429Tallele, and the $(-350 \mathrm{~A})$ allele. ${ }^{13}$ The $\mathrm{G}(-350)$ A polymorphism, which is also in linkage disequilibrium with the C825T polymorphism, is located in the promoter region, but reporter assays with promoter constructs reflecting the (-350)AA and GG genotypes, respectively, yielded no evidence for altered promoter activity associated with these genotypes. Nevertheless, this does not preclude a role of the promoter polymorphism in allele-specific transcription in vivo. Therefore, the major aim of our study was to reinvestigate potential allele-specific transcription of GNB3 using different human cells and tissues. Naturally, the promoter polymorphism cannot be genotyped in mRNA transcripts of GNB3. In addition, mRNA species carrying the C825T polymorphism might escape detection as a region of exon 10, in which this polymorphism is located, is spliced out during the generation of G $\beta 3$-s2. ${ }^{10}$ However, the 825T-allele is in almost complete linkage disequilibrium with the 1429 T-allele in Caucasians ${ }^{13}$ which is located in the $3^{\prime}$-untranslated region of G $\beta 3$ mRNA and, therefore, present in G $\beta 3-$-, G $\beta 3$-s-, and G $\beta 3$-s2-related transcripts. For this reason, we chose to use the C1429T polymorphism, which is also in linkage disequilibrium with the $A(-350) G$ polymorphism, as a marker to quantify allele-specific transcripts of GNB3.

There exist few approaches to quantify allele-specific transcript expression including HaploChip analysis and allele-specific PCR. ${ }^{14,15}$ For our studies, we established an alternative method for allele-specific transcript quantification using Pyrosequencing. The Pyrosequencing technique is based on the detection of released pyrophosphate $\left(\mathrm{PP}_{\mathrm{i}}\right)$ during DNA synthesis. ${ }^{16}$
An enzymatic mixture consisting of sulphurylase and luciferase converts $\mathrm{PP}_{\mathrm{i}}$ to ATP, which then drives the conversion of luciferin to oxyluciferin, yielding detectable light emission, seen as one peak, which is proportional to the amount of incorporated nucleotides. ${ }^{17,18}$ Pyrosequencing was originally developed for the detection of single nucleotide polymorphisms (SNPs), but is now also successfully used for assessing SNP allelic frequencies in DNA mixtures. ${ }^{19,20}$ We, therefore, assumed that the relative amounts of two alleles of a common polymorphism can also be detected on the transcript level by choosing appropriate sequencing primers and dispensation orders of the nucleotides. To test this hypothesis, we first established calibration curves using DNA mixtures with different known ratios of CC and TT genotypes. After validation of the method, we tested our approach for allelic mRNA quantification of the insulin-like growth factor 2 (IGF-2). IGF-2 is an imprinted growth factor that has a major role in fetal development. In most tissues, the paternally derived copy of IGF-2 is expressed, whereas the maternal copy is silent. ${ }^{21}$ It serves as a good candidate for validation of the method because loss of imprinting in certain tumours as well as in peripheral blood cells from healthy subjects has been described..$^{22-24}$ Therefore, complete imprinting as well as partial and total loss of imprinting should be detectable with this method. For allele-specific quantification of the GNB3 1429C- and 1429T-associated mRNA transcripts, we used different cell types and tissues from independent individuals heterozygous for the GNB3 C1429T polymorphism. Finally, we also quantified allele-specific mRNA transcripts associated with the GNB3 $\mathrm{G}(-350)$ A polymorphism in the promoter region.

\section{Materials and methods \\ Genotyping studies of the subjects}

All of the 83 individuals included in this study were genotyped for the C825T, the G(-350)A and the C1429T polymorphism. Genotyping of the polymorphisms was performed as previously described. ${ }^{25}$ For the C825T polymorphism, the sense primer was 5'-TGACCCACTTGCCACCCGTGC- $3^{\prime}$ and the antisense primer was $5^{\prime}$ GCAGCAGCCAGGGCTGGC-3'. Genotypes of the C825T polymorphism were diagnosed by restriction of the PCR amplicon with BseDI (MBI Fermentas, St Leon-Rot, Germany), resulting in two fragments of 115 and $152 \mathrm{bp}$ for the $C$ allele and in an unrestricted fragment of $267 \mathrm{bp}$ for the $\mathrm{T}$ allele. For the C1429T polymorphism, the sense primer was $5^{\prime}$-CAGCCTCTCCCTTAATGAGC- $3^{\prime}$ and the antisense primer was 5'-ACTACTCTGCTCAGAACTCC-3'. The C1429T polymorphism was diagnosed by restriction of the PCR amplicon with BshNI (MBI Fermentas, St LeonRot, Germany), resulting in three fragments of 135, 169, and $305 \mathrm{bp}$ for the $\mathrm{C}$ allele and in two fragments of 135 and 
$474 \mathrm{bp}$ for the $\mathrm{T}$ allele. For the $\mathrm{A}(-350) \mathrm{G}$ polymorphism the sense primer was 5'-AGAGGATGGTGGGGTTGGGAGG-3' and the antisense primer was $5^{\prime}$-GAGGCTGTGAAAGCAGGGGTCAG-3'. The A(-350)G polymorphism was diagnosed by restriction of the PCR amplicon with TaqI (MBI Fermentas, St Leon-Rot, Germany), resulting in two fragments of 91 and $270 \mathrm{bp}$ for the $\mathrm{G}$ allele and in an unrestricted fragment of $361 \mathrm{bp}$ for the A allele.

Genotyping of the IGF-2 ApaI polymorphism was performed with primers I1: 5'-CTTGGACTTTGAGTCAAAT TGG-3' and I3_BT 5'-CCTCCTTTGGTCTTACTGGG-3' as described. $^{26}$

\section{Cells and tissue material}

Adipose tissue was obtained from 22 patients undergoing mamma reduction or gastric banding operation. All adipose tissue samples were immediately snap frozen in liquid nitrogen. Peripheral blood mononuclear cells (PBMCs) from 16 patients with chronic lymphocytic leukaemia (CLL) were isolated by Ficoll-Hypaque (Pharmacia, Erlangen, Germany) density centrifugation. In all, 1 to $2 \times 10^{8}$ PBMCs were used for RNA preparation. Urothelial tumour tissue samples were obtained from 11 patients undergoing transurethral resection or cystectomy due to bladder cancers and tissue was snap frozen in liquid nitrogen directly after dissection. Human Epstein-Barr virus-immortalized lymphoblasts from 17 individuals were grown in RPMI 1640 medium supplemented with $2 \mathrm{mM} \mathrm{L-}$ glutamine (PAA, Pasching, Austria), 10\% fetal bovine serum (PAA, Pasching, Austria), $100 \mathrm{U} / \mathrm{ml}$ pencillin, $100 \mu \mathrm{g} / \mathrm{ml}$ streptomycin (PAA, Pasching, Austria). At $24 \mathrm{~h}$ before RNA preparation, lymphoblasts were subcultured at a density of $5-10 \times 10^{5}$ cells $/ \mathrm{ml}$ into fresh medium and a total of $5-10 \times 10^{6}$ cells was used for RNA preparation. Seven different human retinoblastoma cell lines were provided by the Institute of Cell Biology, University Hospital, Essen, Germany. Cells were grown in DMEM D7777 medium (Sigma, Deisenhoven, Germany) supplemented with $4 \mathrm{~mm}$ L-glutamine, $15 \%$ fetal bovine serum (PAA), $100 \mathrm{U} / \mathrm{ml}$ penicillin, $100 \mu \mathrm{g} / \mathrm{ml}$ streptomycin (PAA), $10 \mu \mathrm{g} / \mathrm{ml}$ insulin (Sigma), and $50 \mu \mathrm{M} \beta$-mercapthoethanol (Sigma, Deisenhoven, Germany). Right atrial specimens were obtained from 15 patients undergoing cardiac surgery. RNA was prepared using the RNeasy Kit obtained from Qiagen (Hilden, Germany) according to the manufacturer's instructions including DNase treatment of all samples.

\section{RT-PCR}

First-strand cDNA was synthesized from $0.5-1 \mu \mathrm{g}$ of total cellular RNA with oligo-dT-primers (Roche, Mannheim, Germany) by using M-MLV reverse transcriptase as recommended (Invitrogen, Karlsruhe, Germany) in a total volume of $20 \mu \mathrm{l}$. The resulting cDNA was diluted 1:10 and $3 \mu \mathrm{l}$ of the dilution was used for PCR. The PCR amplification was performed in a total volume of $50 \mu \mathrm{l}$, Ready-To-Go
PCR beads (Eppendorf, Hamburg, Germany) containing $\sim 1.5 \mathrm{U}$ Taq DNA polymerase, $10 \mathrm{nM}$ Tris- $\mathrm{HCl}$ (pH 9), $50 \mathrm{~mm}$ $\mathrm{KCl}, 1.5 \mathrm{mM} \mathrm{MgCl}_{2}, 200 \mu \mathrm{M}$ of each dNTP. For Pyrosequencing of GNB3 C1429T, biotinylated sense primers: 5'-CAGGCC CAGCAGACTTGA-3' and antisense primers: 5'-GGAGAAA GCATGAATAAGAAGAG-3' were used resulting in a $163 \mathrm{bp}$ PCR product. For IGF-2, PCR was performed using I-1 and biotinylated I-3_BT primers as described above. Amplification of genomic DNA was circumvented by RNA treatment with DNase I (Qiagen, Hilden, Germany) and tested by using RNA as template.

\section{Template preparation and Pyrosequencing assay}

All of the biotinylated PCR product $(25 \mu \mathrm{l})$ was mixed with $25 \mu \mathrm{l}$ of $2 \times$ Binding-Washing buffer II (10 mM Tris- $\mathrm{HCl}, 2 \mathrm{M}$ $\mathrm{NaCl}, 1 \mathrm{~mm}$ EDTA, and 0.1\%. Tween 20, pH 7.6) and $10 \mu \mathrm{l}$ $(10 \mu \mathrm{g} / \mu \mathrm{l})$ streptavidin-coated polystyrene beads. After incubation at $65^{\circ} \mathrm{C}$, DNA was denaturated in $50 \mu \mathrm{l} 0.5 \mathrm{M}$ $\mathrm{NaOH}$. The single-stranded DNA was hybridized to 40 pmol sequencing primer dissolved in $45 \mu \mathrm{l}$ annealing buffer (200 mM Tris-acetate and $50 \mathrm{mM} \mathrm{MgAc}_{2}, \mathrm{pH} 7.6$ ) at $80^{\circ} \mathrm{C}$. For sequencing of GNB3 C1429T, the sequencing primer (5'-CCAGGACCCTAGT-3') was designed for the complementary strand, so that nucleotide ' $A$ ' represents ' $\mathrm{T}$ ', and ' $\mathrm{G}$ ' represents ' $\mathrm{C}$ '. For sequencing of the IGF-2 ApaI polymorphism, the sequencing primer 5'-AGCAAAGA GAAAAGAAGG-3' was used. The Pyrosequencing reaction was carried in a PSQ96 instrument (Pyrosequencing, Uppsala, Sweden). The peak heights were determined using the Pyrosequencing software.

\section{Allele quantification using calibration curves}

DNA concentrations were determined in TNE buffer (10 mM Tris, $0.1 \mathrm{~mm} \mathrm{NaCl}, 1 \mathrm{~mm}$ EDTA, pH 7.4) with Hoechst 33258 dye (Sigma, Deisenhoven, Germany) and calf thymus DNA (Sigma, Deisenhoven, Germany) as standard, as described. ${ }^{27}$ For the C1429T and IGF-2 ApaI polymorphisms, calibration samples were prepared by mixing homozygous DNA samples at different concentrations. PCR from the mixture was carried out with primers as described above. Calibration curves, represented by the plots of the measured versus the expected relative amounts of the certain allele, were generated using linear regression analysis.

\section{Statistical analysis}

All data are expressed as means \pm standard deviation (SD). Continuous variables were compared using the unpaired Student's $t$-test. Differences were regarded significant at $P<0.05$.

Haplotype analysis and control for deviation from the Hardy-Weinberg equilibrium (HWE) were conducted with the public domain programs $\mathrm{EH}$ and HWE by Jürg Ott (http://linkage.rockefeller.edu/ott/eh.htm). Linkage analysis was performed by comparison of the observed and the 
predicted genotype distributions using contingency table analysis ( $\chi^{2}$ tests) testing whether the observed distributions were compatible with a model of independent segregation. The HWE program analyses whether the observed genotype distribution is in accordance with the HWE by calculation of contingency tables. $P$-values $<0.05$ were considered significant to indicate incompatibility with HWE.

\section{Results}

Establishment of a method for allele-specific

quantification of GNB3 transcripts by Pyrosequencing First, we investigated whether the peak heights determined by the pyrogram were actually proportional to the concentration of a specific allele. We used DNA samples from human blood donors who were homozygous for the GNB3 C1429T polymorphism (CC and TT genotypes). DNA samples of CC and TT genotypes were mixed at different known concentrations. PCR was carried out and respective restriction fragments were size fractionated on $2.5 \%$ agarose gels (Figure 1a). The increased ratio of CC genotypes in the DNA mixture resulted in brighter bands of 305,169 , and $135 \mathrm{bp}$. Thereafter, using the same DNA mixtures as template, PCR was carried out and the products were subjected to Pyrosequencing. Representative pyrograms are shown in Figure 1b. It can be seen that the height of the A-peak (corresponding to 1429T) increases with increasing TT/CC ratio in the DNA mixture. The measured

Figure 1 Validation of Pyrosequencing using the GNB3 C1429T polymorphism for allele- specific transcript quantification. (a) A representative agarose gel shows different ratios of the 1429TT/CC genotype DNA after PCR and restriction. Genomic DNA samples from GNB3 1429CC and TT genotypes were mixed to yield the indicated ratios. PCR was carried out and the respective restriction fragments were size fractionated on $2.5 \%$ agarose gel. From left to right, the increased CC genotype DNA content in the mixture results in increasingly stronger bands of 305, 169, and $135 \mathrm{bp}$. (b) Pyrosequencing results of PCR products obtained from DNA mixtures with different CC and TT genotype DNA content. Peak heights were quantified using the Pyrosequencing software. From top to bottom the decreased $\pi$ genotype content results in a lower peak height of the nucleotide A (complementary nucleotide to T; see Materials and methods). (c) Calibration curve for the C1429T polymorphism calculated from the Pyrosequencing analysis of genomic DNA mixtures with known TT/CC ratios. Expected $A$ alleles reflect the known TT/CC ratios of genomic DNA mixtures used for PCR amplification. Measured A alleles were determined from the $A$ peak ratio from the repeated Pyrosequencing analysis. A linear relationship between measured and expected ratios could be confirmed over the whole range investigated. peak heights were plotted against known TT/CC DNA ratios and subjected to linear regression analysis (Figure 1c). We observed an excellent linear correlation between the concentration of the 'A allele' and measured A allele peak heights $\left(y=0.912 \times, R^{2}=0.989, P<0.01\right.$, Figure $\left.1 c\right)$.

To further confirm the validity of the method for quantification of allele-specific transcripts on the mRNA level, we used cells and tissue samples as described in 'Materials and methods' and investigated mRNA expression of the partially imprinted IGF-2 gene. The
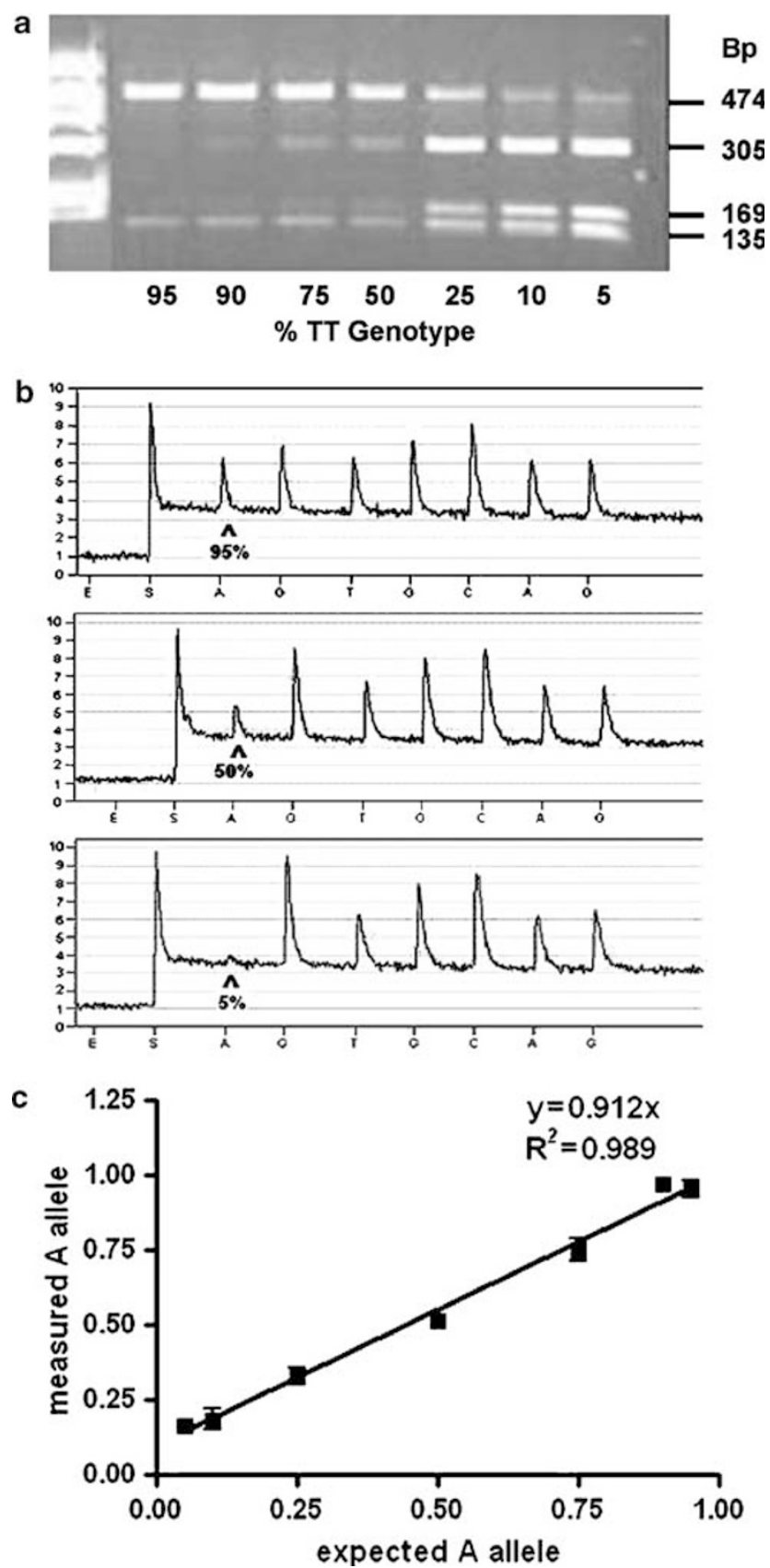
parental origin of the alleles was not determined since we only wanted to investigate allele-specific differences between DNA and mRNA. Again, linear regression analysis was performed on results from homozygous DNA samples mixed at different ratios to prove a linear relationship of the measured and expected allele ratio over a wide range (Figure 2a). A total of 24 DNA samples were heterozygous for the ApaI polymorphism. Ratios were determined using the Pyrosequencing software resulting in a mean fractional allelic expression of 0.49 (95\% CI 0.48-0.51; Figure 2b). On the mRNA level, 10 samples showed complete imprinting (fractional allelic expression $>0.9$ ) with a mean fractional allelic expression of 0.97 (95\% CI $0.94-1.01)$ while the remaining 14 heterozygous samples showed partial or total loss of imprinting (LOI). Expression of the $\mathrm{G}$ allele of samples with LOI ranged from 0.18 to 0.90 (Figure 2b). Interestingly, $93 \%$ of samples with LOI and only $60 \%$ of samples with complete imprinting are derived from
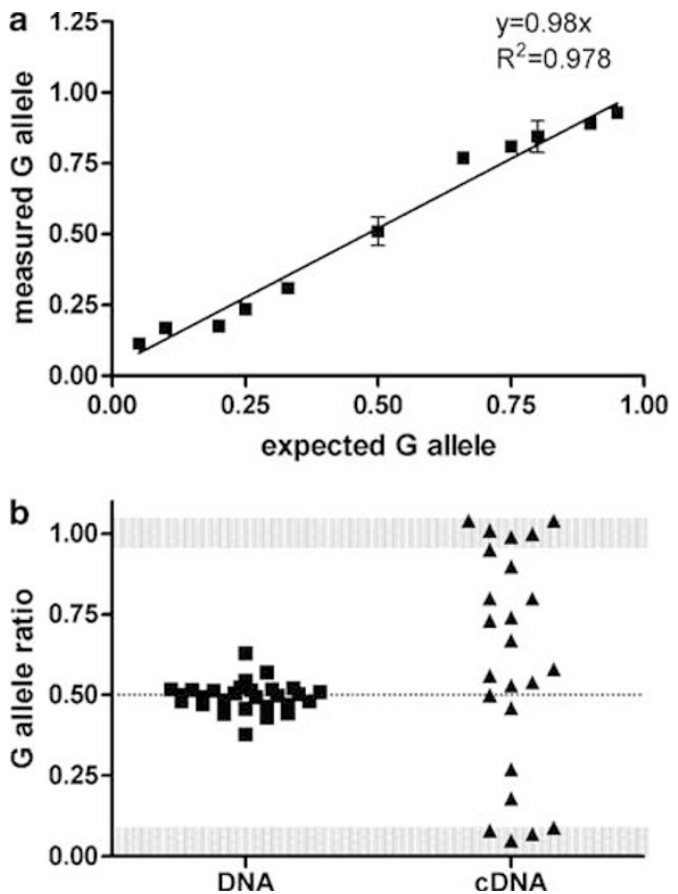

Figure 2 Allele-specific expression of IGF-2. (a) The calibration curve for the Apal polymorphism was calculated from Pyrosequencing analysis of genomic DNA mixture of homozygous samples. Expected $G$ alleles reflect the known fractions of homozygous genomic DNAs used for PCR amplification. Measured $G$ alleles were determined from the $G$ peak ratio from repetitive Pyrosequencing analysis. $A$ linear relationship over the whole range of tested ratios could be confirmed. (b) Comparison of $G$ allele ratios of DNAs and cDNAs from 26 heterozygous samples of the Apal polymorphism. While mean allelic fractions in DNA samples were $0.49(95 \% \mathrm{Cl} 0.48-0.51)$, expression from the $G$ allele in cDNA samples showed a wide variation compatible with differential imprinting of alleles. Complete imprinting is marked with grey bars. lymphoblasts or cancer cell lines and tissues. These results are, therefore, in concordance with earlier studies showing that IGF-2 is biallelically expressed in bone marrow (origin of lymphopoesis) and in certain types of tumour. ${ }^{22-24}$ Thus, Pyrosequencing provides a suitable tool for investigating the extent of LOI in various tissues and cell lines.

Taken together, these findings demonstrate that Pyrosequencing is a reliable method to quantify alleles in a mixture of DNA samples and in cDNAs with unknown ratios of specific alleles. Therefore, this method should also allow to quantify allele-specific transcripts.

\section{GNB3 genotype analysis of the subjects}

In all DNA samples from 83 subjects from whom cells or tissues, respectively, were available, we determine the genotypes for the GNB3 C825T, C1429T, and G(-350)A polymorphisms. For the C825T polymorphism, 40 subjects carried the CC genotype, 33 subjects carried the TC genotype, and 10 individuals carried the TT genotype. The distribution of genotypes for the C825T polymorphism was in accordance with the HWE, and resulted in an $825 \mathrm{~T}$ allele frequency of $31 \%$. For the C1429T polymorphism, 39 subjects carried the CC genotype, 37 subjects carried the TC genotype, and seven individuals carried the TT genotype. The distribution of genotypes of the C1429T polymorphism was again in accordance with the HWE, and resulted in a 1429T allele frequency of 30\%. For the G(-350)A polymorphism, 13 subjects carried the AA genotype, 39 subjects carried AG genotype, and 31 individuals carried the GG genotype. The distribution of genotypes of the $G(-350) A$ polymorphism was also compatible with the HWE with a $(-350)$ A allele frequency of $38 \%$.

There exists an almost complete association of GNB3 $825 \mathrm{~T}$ with $1429 \mathrm{~T}$ and of GNB3 825C with $1429 \mathrm{C}$ $(P<0.001)$, which confirms earlier results. ${ }^{13}$ The GNB3 haplotypes $825 \mathrm{C}-1429 \mathrm{~T}$ and $825 \mathrm{~T}-1429 \mathrm{C}$ occur at negligibly low frequencies (Table 1). The GNB3 polymorphisms $\mathrm{G}(-350) \mathrm{A}$ and C825T are physically separated by $5850 \mathrm{bp}$. Nevertheless, our analysis revealed a significant linkage disequilibrium between these two loci $(P<0.01$; Table 1$)$. For the GNB3 G(-350)A and C1429T polymorphisms, we also observed a significant linkage disequilibrium, which was, however, less tight as that observed for the other two combinations $(P<0.05$; Table 2$)$.

Quantification of allelic variance for the C1429T polymorphism in different tissues and cell lines

We subjected the samples from different tissues and cell lines heterozygous for the C1429T polymorphism to analysis by Pyrosequencing. Using the Pyrosequencing technology, we could determine the exact ratios of $\mathrm{C} / \mathrm{T}$ in both cDNA and genomic DNA. For all genomic DNA samples, the average C/T ratio was calculated at $0.97 \pm 0.14$, which is not significantly different from the theoretical 
Table 1 Linkage analysis of frequent polymorphisms in GNB3 with C825T

\begin{tabular}{lccccl}
\hline Polymorphism & Genotype & $825 C C$ & $825 T C$ & $825 T T$ & $\chi^{2}$ for linkage \\
\hline G(-350)A & $(-350) \mathrm{GC}$ & $13.3(11)$ & $14.5(12)$ & $9.6(8)$ & $825 T-(-350) \mathrm{C}$ and $825 \mathrm{C}-(-350) \mathrm{A}$ \\
& $(-350) \mathrm{GA}$ & $21.6(18)$ & $22.9(19)$ & $2.4(2)$ & $P<0.001$ \\
& $(-350) \mathrm{AA}$ & $13.3(11)$ & $2.4(2)$ & 0 & \\
C1429T & 1429CC & $44.6(37)$ & $2.4(2)$ & 0 & $825 \mathrm{~T}-1429 \mathrm{~T}$ and 825C-1429C \\
& 1429TC & $3.6(3)$ & $37.3(31)$ & $3.6(3)$ & $P<0.01$ \\
& 1429TT & 0 & 0 & $8.4(7)$ & \\
\hline
\end{tabular}

Tables are percentages and absolute numbers (in parentheses).

Table 2 Linkage analysis of G(-350)A with C1429T

\begin{tabular}{lccccl}
\hline Polymorphism & Genotype & $1429 C \mathrm{C}$ & $1429 T C$ & $1429 T T$ & $\chi^{2}$ for linkage \\
\hline $\mathrm{G}(-350) \mathrm{A}$ & $(-350) \mathrm{GG}$ & $13.3(11)$ & $16.8(14)$ & $7.2(6)$ & $1429 \mathrm{~T}-(-350) \mathrm{G}$ and $1429 \mathrm{C}-(-350) \mathrm{A}$ \\
& $(-350) \mathrm{GA}$ & $21.6(18)$ & $24.1(20)$ & $1.2(1)$ & $P<0.05$ \\
& $(-350) \mathrm{AA}$ & $12.0(10)$ & $3.6(3)$ & 0 & \\
\hline
\end{tabular}

Tables are percentages and absolute numbers (in parentheses).

value, that is, unity. For cDNA samples, the highest $\mathrm{C} / \mathrm{T}$ ratios were determined in blood mononuclear cells from patients with CLL $(1.06 \pm 0.17)$, urothelial tumour tissue $(1.04 \pm 0.19)$, and adipose tissue $(1.02 \pm 0.03)$. The lowest ratios were observed in retinoblastoma cell line tissue $(0.84 \pm 0.21)$, while heart tissue $(0.93 \pm 0.01)$ and B lymphoblast cell lines $(0.95 \pm 0.12)$ showed intermediate values. The $\mathrm{C} / \mathrm{T}$ ratio of all cDNA samples was not significantly different from 1 , which argues against a differential transcriptional activity associated with the Cor T-allele. Statistical analysis showed no significant difference in different tissues and cell lines $(P>0.05$; Figure 3).

To investigate the potential influence of the G(-350)A polymorphism on allele-specific transcript expression, we compared the ratios of the heterozygous C1429T samples in all human tissues and cell lines with different $\mathrm{G}(-350) \mathrm{A}$ genotypes (Figure 4 , Table 1 ). The $\mathrm{C} / \mathrm{T}$ ratio in $(-350) \mathrm{GG}$ samples $(1.02 \pm 0.19)$ was identical to that in $(-350) \mathrm{AA}$ samples $(1.01 \pm 0.03)$, while $(-350) \mathrm{AG}$ samples displayed somewhat lower values $(0.94 \pm 0.14$; Figure $4 \mathrm{a})$. Hence, no statistically significant differences were detected between genotypes.

Finally, we compared the C1429T polymorphism C/T ratio in specific human tissues and cell lines with different $\mathrm{G}(-350)$ A genotypes. For blood mononuclear cells from patients with CLL, the $\mathrm{C} / \mathrm{T}$ ratio comprises the largest difference compared to other tissues, with $1.19 \pm 0.23$ in $(-350)$ GG samples and $0.86 \pm 0.17$ in $(-350)$ AG samples. No significant difference was found using $t$-test analysis $(P>0.05)$. For adipose tissues, the $\mathrm{C} / \mathrm{T}$ ratio is nearly equal for different $\mathrm{G}(-350) \mathrm{A}$ genotypes. It was $1.04 \pm 0.01$ in $(-350)$ GG samples, $1.02 \pm 0.05$ in $(-350) A G$ samples, and $1.01 \pm 0.03$ in $(-350)$ AA samples. No significant difference

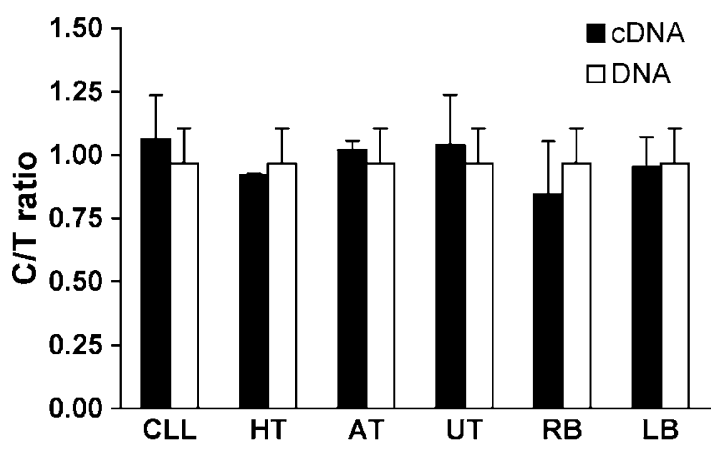

Figure 3 Comparison of 1429 polymorphism C/T ratio of CDNA and DNA from different human tissues and cell lines. CLL: blood mononuclear cells from patients with chronic lymphatic leukaemia $(n=7), \mathrm{HT}$ : heart tissue $(n=2), \mathrm{AT}$ : adipose tissue $(n=11)$, UT: urothelial tumour tissue $(n=4)$, RB: human retinoblastoma cell lines $(n=3)$, LB: B lymphoblast cell lines $(n=6)$. Results argue against different transcriptional activities associated with the C- or T-allele. Data are expressed as means \pm SEM.

was found between the three genotypes $(P>0.05)$. For $\mathrm{B}$ lymphoblast cell lines, again no significant difference was found between $(-350) \mathrm{GG}$ samples $(\mathrm{C} / \mathrm{T}$ ratio $0.82 \pm 0.08)$ and (-350)AG samples (C/T ratio 1.02 $\pm 0.06 ; P>0.05$; Figure $4 b)$.

\section{Discussion}

Pathophysiological significance of the GNB3 C825T polymorphism and unresolved issues

As already outlined in the introduction, the C825T polymorphism has been described as a potentially useful 

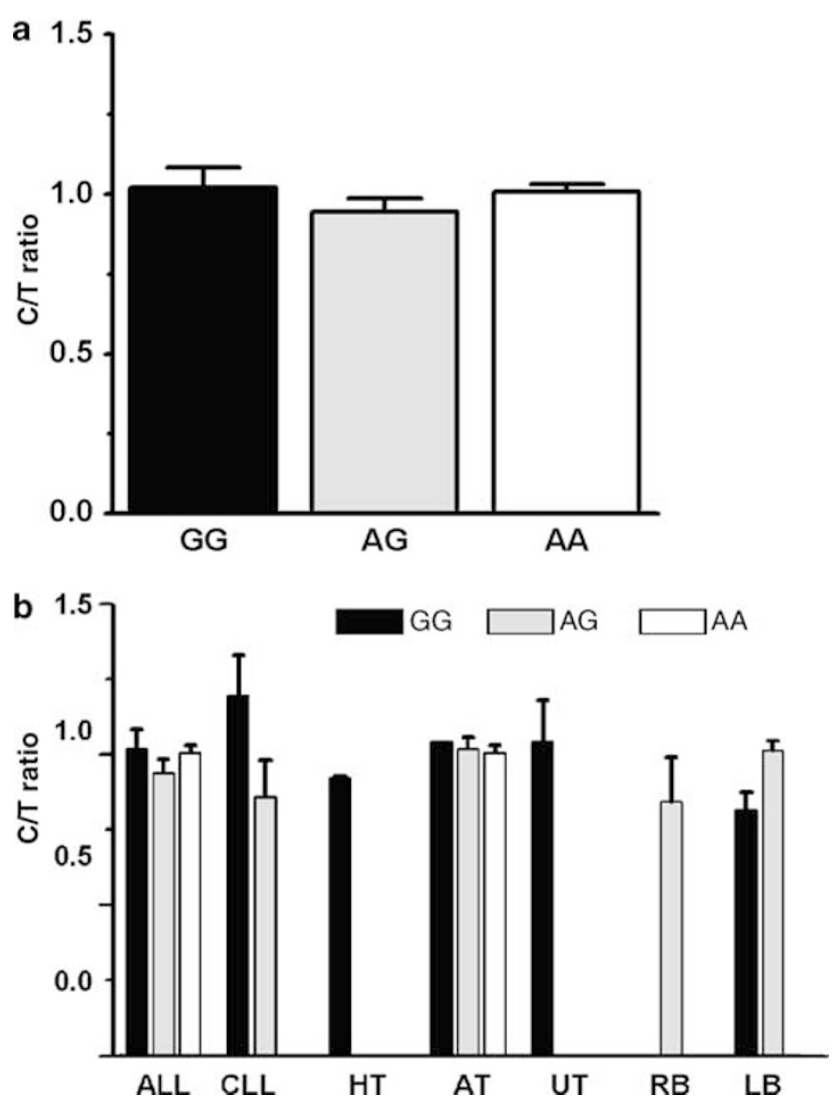

Figure 4 Impact of the $\mathrm{G}(-350) \mathrm{A}$ polymorphism on allele-specific transcript expression. Heterozygous samples of the C1429T polymorphism were stratified by different $G(-350) A$ genotypes and $C / T$ ratios were determined from corresponding cDNAs. (a) cDNAs combined from six human tissues and cell lines. (b) Distribution of $1429 \mathrm{C} / \mathrm{T}$ ratio in CDNAs from specific tissues and cell lines with different $\mathrm{G}(-350)$ A genotype. CLL: blood mononuclear cells from patients with chronic lymphatic leukaemia $(n=7)$, HT: heart tissue $(n=2)$, AT: adipose tissue $(n=11)$, UT: urothelial tumour tissue $(n=4)$, RB: human retinoblastoma cell lines $(n=3)$, LB: B lymphoblast cell lines $(n=6)$. Data are expressed as means \pm SEM.

marker for pharmacogenetic purposes. Moreover, the $825 \mathrm{~T}$ allele has been described to be associated with a variety of disorders. Most studies have focused on hypertension, as this trait was originally associated with the $825 \mathrm{~T}$ allele. ${ }^{6}$ The majority of subsequent studies in Caucasians could confirm these findings ${ }^{28-32}$ while only a few studies in Caucasians refuted an association between 825T carrier status and high blood pressure. ${ }^{33,34}$ In contrast, in East Asian populations, for example, the Japanese and the Chinese, most studies denied an association between the $825 \mathrm{~T}$ allele and an increased risk of hypertension..$^{35-38}$ These discrepant findings may be caused by different facts: the simplest explanation would be that the 825T allele is associated with a specific form of hypertension frequently seen in Caucasians, for example, in association with the metabolic syndrome, ${ }^{32}$ that may be less frequent in East Asian populations. Strong evidence for this notion is still lacking. Alternatively, available data do not rule out the possibility that yet unidentified SNPs or differences in haplotypes between East Asian and Caucasian populations may explain the reported discrepancies. As a matter of fact, the strength of the linkage disequilibrium between the different SNPs found in GNB3 is reduced in black Africans and East Asian subjects compared to Caucasians. ${ }^{13}$ To better understand the potential functional implications of the SNPs and haplotypes found in white subjects was, therefore, one of the major goals of the present report, which focused on potential associations between haplotypes and mRNA expression.

\section{Pyrosequencing as a versatile method for} quantification of allele-specific expression

While Pyrosequencing was originally developed for SNP analysis, the method can also be used for quantification of allele-specific transcript expression. Linear regression analysis clearly supported the notion that the amount of nucleotides incorporated during the sequencing reaction is actually proportional to the peak heights. Furthermore, we were able to validate the method on the mRNA level by investigating the partially imprinted IGF-2 gene (Figure 2). Allelic expression differed largely in different samples. Therefore, this method is a versatile tool for investigation of allele-specific expression as well as for exact determination of the extent of LOI.

\section{C825T allele-specific expression}

Our results confirmed an almost complete association of GNB3 825T with $1429 \mathrm{~T}$ and of GNB3 825C with 1429C from 83 individuals. ${ }^{13}$ The $\mathrm{C}$ and $\mathrm{T}$ alleles of the $\mathrm{C} 1429 \mathrm{~T}$ polymorphism generate almost identical amounts of transcripts in six different human tissues and cell lines. Given the tight linkage disequilibrium between the two polymorphisms, the same must hold true for the $\mathrm{C}$ and $\mathrm{T}$ alleles of the C825T polymorphism. This finding is at odds with the hypothesis that differential allele-specific transcript expression is associated with altered G-protein activity.

As a caveat, it should be mentioned that it is still possible that as yet unidentified SNPs in GNB3 are associated with differential allelic expression. Moreover, from sequencing and association studies of the whole GNB3 gene in different ethnicities ${ }^{13}$ the haplotypes described here show strong linkage disequilibrium only in Caucasians while the association is less strong in East-Asian and black African subjects. In these populations, application of the C1429T SNP as a marker for allele-specific expression may be confounded by as yet unidentified SNPs. 
Ryden $e$ t $a l^{9}$ reported that the total amount of $\mathrm{G} \beta$ subunit protein was not influenced by the GNB3 C825T polymorphism in fat cells, while specifically the expression of $\mathrm{G} \beta_{3}$ protein was markedly decreased in adipocytes from 825T allele carriers. In our experiments, mRNA transcript amounts from the two alleles were virtually identical in all human cell lines and tissues including adipose tissues. It is commonly assumed that SNPs in the $3^{\prime}$-untranslated region of mRNAs may affect their susceptibility to degradation, thereby potentially leading to altered mRNA and/or protein turnover and expression. As the GNB3 C1429T polymorphism is located in the $3^{\prime}$-untranslated region, it could theoretically affect mRNA stability and an increased mRNA degradation associated with the 1429T allele would explain reduced G $\beta 3$ expression. Again, our results do not provide evidence in favour of this assumption.

\section{Function of the $\mathrm{G}(-350) \mathrm{G}$ polymorphism}

The physical distance between the GNB3 G(-350)A polymorphism and the C825T polymorphism is $5850 \mathrm{bp}$. Our results confirmed a significant linkage disequilibrium, in accordance with a published haplotype analysis for black Africans and Germans. ${ }^{13}$ Using a reporter gene assay, previous studies failed to demonstrate a functional impact of the $\mathrm{G}(-350)$ A polymorphism on promoter activity. ${ }^{25}$ In line with these findings, we found no association of genotypes of the $G(-350) A$ polymorphism with transcript levels in our experiments. Hence, the observed reduced $\mathrm{G} \beta 3$ protein expression in fat cells from 825T allele carriers remains unexplained. As a caveat, we must state that our method for quantification of mRNA transcripts was designed to detect both wild-type mRNA as well as mRNAs encoding for the splice variants $G \beta 3$-s and G $\beta 3$ s- 2 in order to see potential regulatory influences of SNPs in the promoter and $3^{\prime}$ untranslated regions of GNB3. Although transfection and reconstitution studies have shown that these splice variants may be stable and can dimerize with $\mathrm{G} \gamma$ subunits, ${ }^{10,11}$ these results have been obtained from systems in which these splice variants were overexpressed and, thereby, eventually, their enhanced degradation was compensated by increased production. It is, therefore, still thinkable that G $\beta 3$-s and G $\beta 3$-s2 mRNAs, which can be detected in many tissues by means of RT-PCR, ${ }^{10,11}$ are less stable than wild-type G $\beta 3$ mRNA. Their preferential degradation and/or reduced translation into protein or lack of stability of G $\beta 3$-s and G $\beta 3$-s2 protein under in vivo conditions would macroscopically result in reduced $\mathrm{G} \beta 3$ protein expression in cells from $825 \mathrm{~T}$ allele carriers in which these splice variants are predominantly expressed. Additional experiments are required to answer these questions.
Potential application of Pyrosequencing for assessing functional consequences of SNPs in regulatory regions The regulatory impact of SNPs located in the promoter region is usually examined by in vitro assays like a reporter gene assay. However, functional consequences may be not detected by such assays if the cell system used for expression of the reporter gene construct is inappropriate, for example, due to lack of endogenous expression of suitable transcription factors, or if conditions or agonists for stimulation of promoter activity are unknown or inappropriately chosen. Moreover, the validity of the assays can under certain circumstances be confounded by lack of the natural confirmation and regulation of the promoter sequence. In addition, absence or presence of additional undetected SNPs or haplotypes may be responsible for different promoter regulation in vitro versus in vivo. Recently, alternative 'in vivo' assays have been developed, which may decrease the effect of such confounding factors. HaploChIP analysis requires that suitable cells or tissues are available and that the regulatory variant is in the heterozygous state. ${ }^{14}$ However, this assay is laborious and not easily carried out. Another method uses allele-specific RT-PCR which, however, relies on the presence of an exonic polymorphism which should be in linkage disequilibrium with the regulatory SNP under investigation. The same restraint comes into play with the Pyrosequencing technique described here. Nevertheless, the results presented here support the notion that Pyrosequencing provides an accurate and valid approach for allelespecific mRNA quantification.

\section{References}

1 Turner ST, Schwartz GL, Chapman AB, Boerwinkle E: C825T polymorphism of the $\mathrm{G}$ protein beta(3)-subunit and antihypertensive response to a thiazide diuretic. Hypertension 2001; 37 (Part 2): 739-743.

2 Zill P, Baghai TC, Zwanzger P et al: Evidence for an association between a G-protein beta3-gene variant with depression and response to antidepressant treatment. Neuroreport 2000; 11: $1893-1897$.

3 Sperling H, Eisenhardt A, Virchow S et al: Sildenafil response is influenced by the $G$ protein beta 3 subunit GNB3 C825T polymorphism: a pilot study. J Urol 2003; 169: 1048-1051.

4 Nurnberger J, Dammer S, Mitchell A et al: Effect of the C825T polymorphism of the $G$ protein beta 3 subunit on the systolic blood pressure-lowering effect of clonidine in young, healthy male subjects. Clin Pharmacol Ther 2003; 74: 53-60.

5 Hauner H, Meier M, Jockel KH, Frey UH, Siffert W: Prediction of successful weight reduction under sibutramine therapy through genotyping of the G-protein beta3 subunit gene (GNB3) C825T polymorphism. Pharmacogenetics 2003; 13: 453-459.

6 Siffert W, Rosskopf D, Siffert G et al: Association of a human G-protein beta3 subunit variant with hypertension. Nat Genet 1998; 18: $45-48$.

7 Virchow S, Ansorge N, Rubben H, Siffert G, Siffert W: Enhanced fMLP-stimulated chemotaxis in human neutrophils from individuals carrying the $\mathrm{G}$ protein beta3 subunit 825 T-allele. FEBS Lett 1998; 436: 155-158.

8 Lindemann M, Virchow S, Ramann F et al: The G protein beta3 subunit $825 \mathrm{~T}$ allele is a genetic marker for enhanced $\mathrm{T}$ cell response. FEBS Lett 2001; 495: 82-86. 
9 Ryden M, Faulds G, Hoffstedt J, Wennlund A, Arner P: Effect of the (C825T) Gbeta(3) polymorphism on adrenoceptor-mediated lipolysis in human fat cells. Diabetes 2002; 51: 1601-1608.

10 Rosskopf D, Manthey I, Habich C et al: Identification and characterization of $G$ beta $3 \mathrm{~s} 2$, a novel splice variant of the G-protein beta 3 subunit. Biochem J 2003; 371 (Part 1): 223-232.

11 Rosskopf D, Koch K, Habich C et al: Interaction of Gbeta3s, a splice variant of the G-protein Gbeta3, with Ggamma- and Galpha-proteins. Cell Signal 2003; 15: 479-488.

12 Ruiz-Velasco V, Ikeda SR: A splice variant of the G protein beta 3-subunit implicated in disease states does not modulate ion channels. Physiol Genomics 2003; 13: 85-95.

13 Rosskopf D, Manthey I, Siffert W: Identification and ethnic distribution of major haplotypes in the gene GNB3 encoding the G-protein beta3 subunit. Pharmacogenetics 2002; 12: 209-220.

14 Knight JC, Keating BJ, Rockett KA, Kwiatkowski DP: In vivo characterization of regulatory polymorphisms by allele-specific quantification of RNA polymerase loading. Nat Genet 2003; 33: 469-475.

15 Yan H, Yuan W, Velculescu VE, Vogelstein B, Kinzler KW: Allelic variation in human gene expression. Science 2002; 297: 1143.

16 Ronaghi M, Karamohamed S, Pettersson B, Uhlen M, Nyren P: Real-time DNA sequencing using detection of pyrophosphate release. Anal Biochem 1996; 242: 84-89.

17 Ronaghi M, Uhlen M, Nyren P: A sequencing method based on real-time pyrophosphate. Science 1998; 281: 363-365.

18 Ahmadian A, Gharizadeh B, Gustafsson AC et al: Single-nucleotide polymorphism analysis by pyrosequencing. Anal Biochem 2000; 280: 103-110.

19 Gruber JD, Colligan PB, Wolford JK: Estimation of single nucleotide polymorphism allele frequency in DNA pools by using Pyrosequencing. Hum Genet 2002; 110: 395-401.

20 Wasson J, Skolnick G, Love-Gregory L, Permutt MA: Assessing allele frequencies of single nucleotide polymorphisms in DNA pools by pyrosequencing technology. Biotechniques 2002; 32: $1144-1146,1148,1150$.

21 Efstratiadis A: Parental imprinting of autosomal mammalian genes. Curr Opin Genet Dev 1994; 4: 265-280.

22 Morison IM, Eccles MR, Reeve AE: Imprinting of insulin-like growth factor 2 is modulated during hematopoiesis. Blood 2000; 96: $3023-3028$

23 Cui H, Cruz-Correa M, Giardiello FM et al: Loss of IGF2 imprinting: a potential marker of colorectal cancer risk. Science 2003; 299: $1753-1755$

24 Wu HK, Weksberg R, Minden MD, Squire JA: Loss of imprinting of human insulin-like growth factor II gene, IGF2, in acute myeloid leukemia. Biochem Biophys Res Commun 1997; 231: 466-472.
25 Rosskopf D, Busch S, Manthey I, Siffert W: G protein beta 3 gene: structure, promoter, and additional polymorphisms. Hypertension 2000; 36: 33-41.

26 Sakatani T, Wei M, Katoh $\mathrm{M}$ et al: Epigenetic heterogeneity at imprinted loci in normal populations. Biochem Biophys Res Commun 2001; 283: 1124-1130.

27 Labarca C, Paigen K: A simple, rapid, and sensitive DNA assay procedure. Anal Biochem 1980; 102: 344-352.

28 Schunkert H, Hense HW, Doring A, Riegger GA, Siffert W: Association between a polymorphism in the $G$ protein beta3 subunit gene and lower renin and elevated diastolic blood pressure levels. Hypertension 1998; 32: 510-513.

29 Hengstenberg C, Schunkert H, Mayer B et al: Association between a polymorphism in the G protein beta3 subunit gene (GNB3) with arterial hypertension but not with myocardial infarction. Cardiovasc Res 2001; 49: 820-827.

30 Benjafield AV, Jeyasingam CL, Nyholt DR, Griffiths LR, Morris BJ: G-protein beta3 subunit gene (GNB3) variant in causation of essential hypertension. Hypertension 1998; 32: 1094-1097.

31 Beige J, Engeli S, Ringel J, Offermann G, Distler A, Sharma AM: Donor $\mathrm{G}$ protein beta3 subunit 825TT genotype is associated with reduced kidney allograft survival. J Am Soc Nephrol 1999; 10: $1717-1721$.

32 Brand E, Wang JG, Herrmann SM, Staessen JA: An epidemiological study of blood pressure and metabolic phenotypes in relation to the Gbeta3 C825T polymorphism. J Hypertens 2003; 21: 729-737.

33 Brand E, Herrmann SM, Nicaud V et al: The $825 \mathrm{C} / \mathrm{T}$ polymorphism of the G-protein subunit beta3 is not related to hypertension. Hypertension 1999; 33: 1175-1178.

34 Snapir A, Heinonen P, Tuomainen TP et al: G-protein beta3 subunit C825T polymorphism: no association with risk for hypertension and obesity. J Hypertens 2001; 19: 2149-2155.

35 Ishikawa $\mathrm{K}$, Imai $\mathrm{Y}$, Katsuya $\mathrm{T}$ et al: Human G-protein beta3 subunit variant is associated with serum potassium and total cholesterol levels but not with blood pressure. Am J Hypertens 2000; 13: 140-145

36 Shioji K, Kokubo Y, Mannami $\mathrm{T}$ et al: Association between hypertension and the alpha-adducin, beta1-adrenoreceptor, and G-protein beta3 subunit genes in the Japanese population; the Suita study. Hypertens Res 2004; 27: 31-37.

37 Suwazono Y, Okubo Y, Kobayashi E et al: Lack of association between human G-protein beta3 subunit variant and overweight in Japanese workers. Obes Res 2004; 12: 4-8.

38 Huang $\mathrm{X}, \mathrm{Ju} \mathrm{Z}$, Song $\mathrm{Y}$ et al: Lack of association between the $G$ protein beta3 subunit gene and essential hypertension in Chinese: a case-control and a family-based study. $J$ Mol Med 2003; 81: 729-735. 